\title{
Housing Correlates of Under-Five Mortality in Urban Ethiopia
}

\author{
Hadgu Bariagabera
}

\begin{abstract}
Little studies and analysis have been undertaken to investigate the housing determinants of under-five mortality in Ethiopia. This study, therefore, explores the impacts of urban housing variables on the levels and patterns of under-five mortality in the country based on the SPSS (Statistic Package for Social Science) file of the 2005 Ethiopian Demographic and Health Survey (EDHS). This survey covered a sample of about 4,420 households/housing units of urban Ethiopia. The under-five deaths are computed for women in the age group 15-49 by subtracting the number of children living from children ever born (CEB) and established the proportion dead by dividing deaths by CEB corresponding to the categorical variables of housing structure, facilities, and household durables. The analytical techniques of the study included univariate, bivariate, and multivariate data analysis of the proportional variations of childhood mortality patterns being manifested by "bar graphs" with respect to housing situations as well as household durables. Amongst the categorical variables of the housing structures, facilities, and household durables with the highest no prevalence of under-five mortality levels are found to be the units of unconventional walls, thatched/leaf/reed roofing, animal dung flooring, shared pit latrine/use of bucket/bush, using kerosene, firewood/straw/charcoal for cooking, unconventional lighting, unprotected water supply, households with no durables.
\end{abstract}

\section{Keywords}

Housing, under-five mortality, correlates, descriptive statistics

Urbanization: A summary of the UN (United Nations) classification of urban localities comparing with the Ethiopian population census classifications of urban delineation is presented in the following table (see Table 1).

As shown in Table 1, the UN minimum size of an urban environment is 20,000 and over inhabitants, while Africa's definition is generally a minimum concentration of non-agricultural population with 2,000 and over inhabitants, similar to the pattern of Ethiopia's definition (refer to Table 1). Even with such minimum size of an urban definition, the continental level of urbanization has been very low, ranging from as low as $15 \%$ for East and $30 \%$ for
Middle African countries, with Ethiopia having had recorded about $16 \%$ as of the last 2007 population and housing census out of the total national population (United Nations Economic Commission for Africa [UNECA] 1995; Central Statistical Agency [CSA] 2007).

Paradoxically, African's urban growth rate has been

aUniversity of Botswana, Botswana

\section{Correspondent Author:}

Hadgu Bariagaber, Faculty of Social Sciences, Department of Population Studies, University of Botswana, P/Bag UB 00705, Block 240, Office 241, Gaborone, Botswana E-mail: hadgub84@gmail.com 
the highest in the world, ranging from $4.5 \%$ for Southern Africa to $5.5 \%$ for East African states, giving about 5\% for Ethiopia. However, Africa's urbanization is generally characterized by the formation of one or two primate cities (Addis Abeba is a typical example), which manifests various urbanization problems, including housing situations and facilities with slum/squatter settlement patterns and commonly observed overcrowded single-room houses and other conditions which have been detrimental to the health of the urban population (Sokoma 1985; Ministry of Urban Development and Housing [MUDH] 1980; Hamdan 1964).

\section{UNDER-FIVE MORTALITY}

Children of the poorest families and those whose mothers are less educated, were found to be more likely to die, though these factors still remain valid issues to the developed regions as well. In these areas, the variables which showed influencing under-five mortality levels were sex of the child, age of the mother at delivery, birth order, mother's educational level, those born to teenage mothers and poor child spacing (Obcraft and McDonald 2010; The Guardian 1990). Other factors of under-five mortality include nutritional deficiency over a long period of time, consisting of three standard indicators, namely, stunting, wasting, and underweight. These variables are strongly correlated with vulnerability to diseases, resulting in delayed physical and mental development, developing chronic diseases in later life worldwide, with the majority being in Africa and South-East Asia (UN Inter-agency Group for Child Mortality Estimation 2012).

Since the low literacy rates and education among women correlate strongly with high rates of under-five mortality, the education of women, their promotion to good working environment and good pay with adequate maternity protection, etc., are necessary factors for successful promotion of children's nutritional status and health care. Furthermore, expansion of immunization programmes against specific pathogens, adequate nutrition, including inclusive breastfeeding for the newly born babies during the first six months of life and measures to reduce indoor air pollution are among the most important preventive measures for reducing the neonatal and childhood mortality levels (Black et al. 2013; World Health Organization [WHO]/World Bank 2004; UN Children's Fund/WHO 2004; Dherani 2008; Smith et al. 2011).

Considering the case of Ethiopia, although it is reported that the country has so far reduced under-five mortality by more than $67 \%$ as of 1990 , still remains an increasing number of childhood deaths, attributable to newborn deaths (those in the first 28 days of life). For example, a study in Butajira on about 600 deaths of under-five children was carried out among a population of 28,780 and results showed that diarrhoeal disease, acute respiratory infections, pneumonia, malaria, and HIV (Human Immunodeficiency Virus)/AIDS (Acquired Immune Deficiency Syndrome) were found to be among the major probable causes of deaths (UN/Nations International Children's Emergency Fund [UNICEF] 2012; Ram 2012).

In the same vein, Kumar and File (2010) analyzed the level of under-five mortality in Ethiopia based on about 14,000 women in the age group 15-49, covered by the 2005 Ethiopian Demographic Survey and found out that the main predictors of infant and childhood were mother's education and income, birth order and to some extent, mother's age and urban/rural residence (Kumar and File 2010).

On the other hand, it was noted that political instability, recurrent emergencies and disasters, widespread extreme poverty, and some of the lowest budgetary allocations to basic social services in the developing world, like Africa, have contributed to the dismal child survival rates in these regions and that without faster progress in all regions, it will take until 
Table 1. Criteria for Urban Definitions

\begin{tabular}{llll}
\hline & International/UN classifications & \multicolumn{2}{c}{ Ethiopia's national urban classifications } \\
\hline Category & Size/Class & Category & Size/Class \\
\hline Proper urban & $20,000+$ & Sub-city for census & $1,000-2,000$ \\
Metropolis & $50,000+$ & Small towns & $2,000-49,999$ \\
City & $100,000+$ & Medium & $50,000-99,999$ \\
Big city & $5,000,000+$ & Large city & $100,000+$ \\
Megalopolis & 10 million+ & Addis Abeba & 4 million+ \\
\hline
\end{tabular}

2028 for the world (e.g., Africa) to meet the Millenium Development Goals-MDG4 target (UNICEF 2012).

In inclusion, the foregoing section tried to indicate some important causes of the components of under-five mortality levels and patterns. However, there appears a research gap on the impact of housing variables on the infant and childhood mortality conditions. The author is, therefore, motivated to consider and analyze the impact of housing variables on under-five mortality, taking urban Ethiopia as a case in the forthcoming sections of this paper.

\section{THE SETTING UP OF THE STUDY}

\section{General Demographic Background of Ethiopia}

Ethiopia has so far undertaken three modern national population and housing censuses. The first census ever taken was in 1984, followed by 1994 and 2007, respectively. A summary of the salient demographic features of the country is presented in Table 2.

In terms of population size, the country stands second to Nigeria in the African continent. As indicated in the table, Ethiopia is demographically typical of the developing societies, characterized by low level of urbanization, high population growth, high fertility level, and low life expectancy at birth which reflects the prevalence of high mortality level which underlies high infant and childhood mortality conditions. Assuming a growth rate of $2.6 \%$, the population of the country could double in a matter of about every 27 years. This means that the population of Ethiopia would be about 147.6 million by the year 2031 and this calls for all demographic, environmental, social, and economic developmental efforts and relevant policy actions to accelerate in order to keep pace with the projected rapid population growth.

\section{Levels of Early Childhood Mortality}

Mortality levels. The components of the under-five mortality are Neonatal (NN), Post-Neonatal (PNN), Infant and childhood mortality levels, defined as shown in the notes ${ }^{1}$. Table 3 summarizes the early childhood mortality levels, showing that the infant mortality rate was 59 per 1,000 live births and the under-five mortality rate was 88 per 1,000 live births. This implies that one in every 17 Ethiopian children dies before their first birthday and one in every 11 Ethiopian children dies before celebrating their fifth birthday, implying that there needs high health development efforts in the country.

\section{Rationale/Justification, Objectives, and Problem Statement of the Study}

Rationale. Little in-depth studies and analysis have been done on the housing determinants of infant and childhood mortality, despite the fact that the country has collected enough empirical housing data from the previous three national population and housing censuses and three Demographic and Health Surveys 
Table 2. Summary of Basic Demographic Indicators of Ethiopia

\begin{tabular}{|c|c|c|c|}
\hline \multirow{2}{*}{ Major demographic variables } & \multicolumn{3}{|c|}{ Basic demographic indicators corresponding to census dates } \\
\hline & 1984 & 1994 & 2007 \\
\hline Population (million) & 42.6 & 53.5 & 73.8 \\
\hline Level of urbanization (\%) & 11.4 & 13.7 & 16.1 \\
\hline Pop growth rate (\%) & 3.1 & 2.9 & 2.6 \\
\hline Total Fertility Rate (TFR) & 6.5 & 6.0 & 5.5 \\
\hline \multicolumn{4}{|l|}{ Life expectancy } \\
\hline Male & 51.1 & 50.9 & 56.3 \\
\hline Female & 53.4 & 53.5 & 58.5 \\
\hline Sex ratio at birth & 104.0 & 103.0 & 103.0 \\
\hline
\end{tabular}

Note: Sources: Compiled from the 1984, 1994, and 2007 Population and Housing Census Reports.

Table 3. Early Childhood Mortality Levels (Ethiopia Demographic and Health Surveys 2000-2011)

\begin{tabular}{llllll}
\hline \multirow{2}{*}{$\begin{array}{l}\text { Years preceding } \\
\text { survey (2011) }\end{array}$} & \begin{tabular}{l} 
Early childhood mortality rates \\
Neonatal mortality \\
\cline { 2 - 6 }
\end{tabular} & $\begin{array}{l}\text { Post-neonatal } \\
\text { mortality } \\
(\mathrm{PNN})\end{array}$ & $\begin{array}{l}\text { Infant mortality } \\
\left(1 \mathrm{q}_{0}\right)\end{array}$ & $\begin{array}{l}\text { Childhood mortality } \\
\left(4 \mathrm{q}_{1}\right)\end{array}$ & $\begin{array}{l}\text { Under-five } \\
\left(5 \mathrm{q}_{0}\right)\end{array}$ \\
\hline $0-4$ & 37 & 22 & 59 & 31 & 88 \\
$5-9$ & 48 & 40 & 88 & 49 & 133 \\
$10-14$ & 54 & 47 & 101 & 72 & 166 \\
DHS years & $\mathrm{NN}$ & PNN & Infant & Childhood & Under-five \\
2000 & 49 & 48 & 97 & 77 & 166 \\
2005 & 39 & 38 & 77 & 50 & 123 \\
2011 & 37 & 22 & 59 & 31 & 88 \\
\hline
\end{tabular}

Note: Sources: Compiled from the 2000, 2005, and 2011 EDHS (Ethiopian Demographic and Health Survey) Programmes.

(DHS). The focus of this paper is, therefore, unique in the sense that examinations of the variations of childhood mortality are going to be explored in the urban structure of Ethiopia with respect to housing characteristics, namely, housing structure/situation, facilities, and household durables using the SPSS (Statistic Package for Social Science) Data files of 2005 EDHS (Ethiopian Demographic and Health Survey), which covered, among other data of interest, a sample of about 4,400 households/housing units.

Objectives. The main objective of the study included is to indicate to urban planners in general and other bodies to be engaged in housing design and construction in particular to take note of the effect of housing on mortality conditions, with particular attention to under-five mortality conditions.

Problem statement. There had been persistent high mortality conditions in Sub-Saharan Africa in general and Ethiopia in particular and this trend could be conjectured to continue for some decades before coming down to acceptable levels. The main reasons could be noted to be largely due to the widespread poverty conditions and low level of health services in urban/rural Sub-Saharan Africa. In particular, it had been apparent that persistently high infant mortality induces high fertility level, for women tend to increase their fertility performance in order to compensate the 
loss of high infant mortality, which is termed as "replacement effects".

The reciprocal relationship between high infant mortality and high fertility levels has been such that fertility tends to be superior to the level of infant mortality and follows by relatively high survivors which results in again having a youthful population, leading to high dependency ratio (burden) on the productive segment of the population. Eventually, the increase in the reproductive segments of the population as well as producing high growth potentials, would subsequently result in significant detrimental effects on developmental endeavours, aggravating poverty with concomitant effect on health service provisions with concomitant effects on levels of childhood mortality.

\section{The General Conceptual Framework and Analytical Techniques}

Housing conditions are covariates of the level of living conditions which influence the status of mortality in general and infant and childhood mortality in particular. A simplified general conceptual approach is hereby presented in Figure 1, manifesting the complex reciprocal interaction among socio-economic, housing, and demographic variables. In-built in the central framework is the infant and childhood mortality box being affected by socio-economic and demographic factors through housing variables. In this connection, Moni Nag (1988) provided detail components of analytical framework of factors affecting neonatal, post-neonatal, and infant deaths such as the demographic (e.g., maternal age), socio-economic (e.g., mother's education), environmental sanitation and personal hygiene (e.g., housing condition), nutritional availability (e.g., mother's caloric food intake), and medical care, inclusive of prenatal care, neonatal and post-neonatal immunization (Nag 1988).

With respect to analytical methods, this paper considers three stages: (1) univariate; (2) bivariate; and (3) multivariate data analysis. Simple descriptive and proportionality of variation among the categories of each housing characteristic (e.g., type of floor, toilet facility, etc.) with respect to relative infant and childhood mortality level be applied where the univariate and bivariate analysis would deal with the types, levels, and characteristics of urban services, whereas the latter would focus on the housing determinants of infant and childhood mortality levels and patterns. From the analysis, we would be able to identify the most critical categorical variables of the housing situations, housing facilities, and household service durables which would likely appear to influence under-five mortality.

\section{COMPILATION AND CONSTRUCTION OF DATA AND ANALYSIS}

In order to keep abreast with timely data requirements for short- and long-term development planning, the Central Statistical Agency (CSA) of Ethiopia has been conducting series of demographic sample surveys in order to fill the intercensal gaps in population composition and population dynamics. Among the demographic sample surveys, include conducting series of DHS with special reference to the incidence and prevalence of HIV/AIDS pandemic and other opportunistic diseases such as Sexually Transmitted Infections (STIs), Tuberculosis (TB), and other non-HIV infectious diseases. The source of data of the analytical study is the SPSS data file of the 2005 EDHS.

The output of this survey is found to be unique from other EDHS in that it covered about 14,000 women in the productive and reproductive age segment of 15-49, rural and all classifications of urban setting in the country with corresponding data on children ever born (CEB) and surviving for each woman in the age group 15-49.

From the retrospective data of CEB and surviving, 


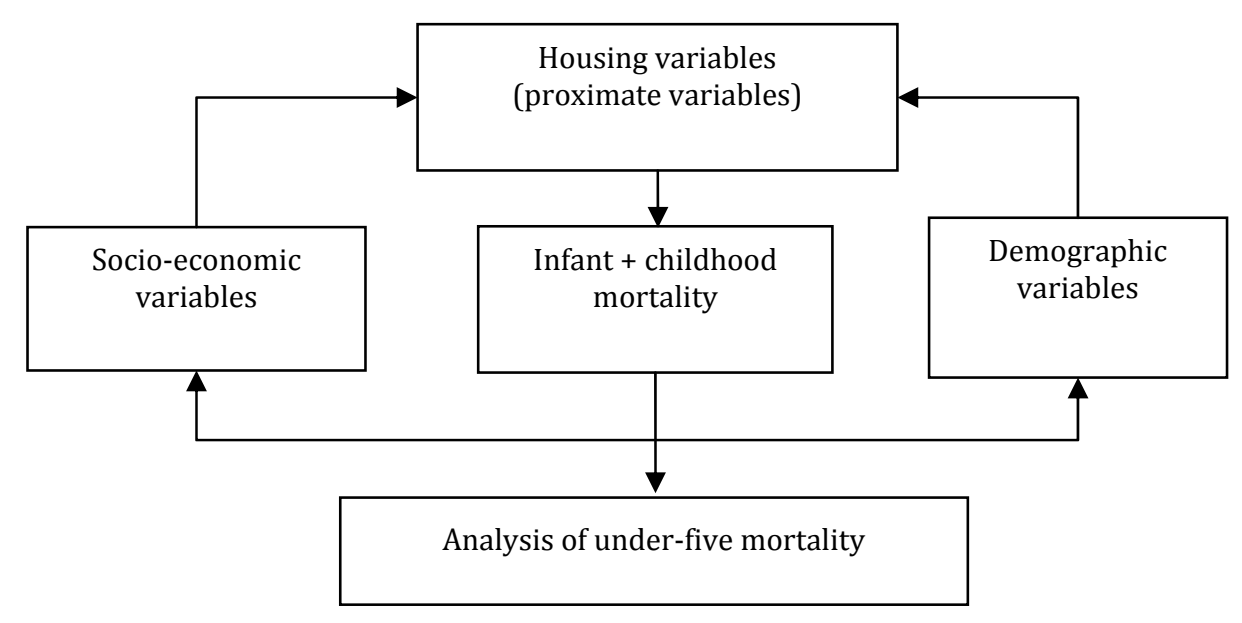

Figure 1. Conceptual Framework Manifesting the Antecedent and Proximate Determinant of Infant and Childhood Mortality.

the author was able to construct the corresponding number of children dead, forming proportion of dead by dividing number of children dead by corresponding CEBs, covering 4,420 households/housing units (housing situation/structure: types of wall, floor, roof, etc.), housing facilities (water, toilet, kitchen, etc.), and housing communication (durables such as radio, telephone, and TV). The analysis is, therefore, organized under three main analytical levels, namely, frequency distribution of housing conditions and examination of the impact of the housing categorical variables on under-five mortality.

\section{Univariate and Bivariate Frequency} Distribution of Housing Structure and Facilities of Addis Abeba and Other Urban Areas

Addis Abeba. Despite the fact that the city has been receiving the largest share of the national human and material resources, the city has been characterized by a number of deplorable unhealthy housing conditions.
A summary of the results is presented in Table 4. In order to upgrade and renew the existing situation of the city to acceptable standard, it calls for huge human and material resources. On top of that, the city's population has been growing rapidly due to rural and other urban migration which would compound the city's problems.

Other urban areas. The univariate and bivariate frequency distribution of the housing conditions (housing structure, facilities, and household durables) of the urban areas are presented in Appendix and summarized in Tables 18-20:

(1) Most of the materials of floor are made of carpet/earth/dung (specially with small towns) which are full of dusts, detrimental to child health;

(2) Material constructions of walls are mostly bamboos/woods/mud in all urban areas;

(3) Materials for roofing are mostly corrugated iron sheets, though some thatched/leave/reed roofs in small towns;

(4) Water supply facilities are mostly outside 
Table 4. Summary of Housing Situation and Facilities of Addis Abeba

\begin{tabular}{llll}
\hline Housing facility & Percent out of total & Housing structure/situation & Percent out of total \\
\hline Kitchen facility & & & \\
\hline Traditional & 67.8 & Wood/mud/thatched walls & 84.4 \\
Modern & 6.0 & Floor of earth/mud & $53-56$ \\
Rooms used as kitchen & 46.9 & Cooking: fire wood/dung & 53.4 \\
No kitchen & 26.2 & Using kerosene for lighting & 10.3 \\
& & Renting households & 60.6 \\
\hline Water supply & & & \\
\hline Private tap & $27-29$ & Overcrowding indicators & \\
No bathing & 85.8 & 3+ persons per room & 41.7 \\
Using well/river/spring & $19-22$ & Doubled up households & 19.3 \\
\hline Toilet facility & & & \\
\hline Flush toilet & 12.0 & & \\
Dry pits & $73-77$ & & \\
No toilets & $24-30$ & & \\
\hline
\end{tabular}

compound, being shared among households but unprotected well/spring, specially in small towns;

(5) Toilets are mostly shared pit latrine, use of buckets and bush;

(6) Cooking facilities are kerosene, firewood straw, and charcoal;

(7) Power is available with significant coverage in big and medium cities, but about only one-third of households in small towns have electric power.

Durables. Availability of radio is significantly high in all urban classifications, but having significantly low proportions in telephone and TV in medium and very low in small towns.

In conclusion, from the univariate and bivariate frequency distribution tables of the housing structure/situation, facilities, and household communication durables of Addis Abeba and other urban areas have been characterized by the following manifestations:

(1) Prevalence of deplorable housing shortages, poor environmental sanitation, unhealthy overcrowding in terms of person/room ratios;

(2) Congestion with high rate of household tenancy and unacceptable waste disposal practices;

(3) Unhealthy housing conditions with doubled up households, sharing the same facilities;

(4) Inadequate and qualitatively inefficient water supply system;

(5) Sub-standard unacceptable toilet facilities;

(6) Serious lack of modern kitchen facilities associated with poor cooking fuel facilities.

\section{Impact of Housing Variables on Under-Five Mortality}

Mortality is one of the components of the demographic dynamics. It plays important role in the determination of population growth and demographic transition concept, for it is the outcome of the interplay among various biological, environmental, economic, and socio-cultural factors.

This section, therefore, deals with the influence of housing conditions on the mortality levels of under-five children in urban Ethiopia. From the SPSS data file of 2005 EDHS, the proportions of children dead are computed from the difference between CEB and children living, controlled for urban areas, 
housing conditions, and established proportion of dead against the categorical variables of housing situation, facilities, and household durables under sections, with details in tabular forms and corresponding graphs (see Tables 5-8 and Figures 2-5).

Impact of housing structure on under-five mortality level. The dependent variable of this study is the mortality level of "under five" and the independent variables are going to be the categorical variables of the housing structures, facilities, and household durables. This sub-section examines the correlates of urban classifications and the housing conditions (comprising mainly the material of construction of walls, floor, and roofing) with under-five childhood mortality of urban Ethiopia. The results are summarized in Tables 5-8, with their respective graphical representations (see Figures 2-5).

\section{Impact of Housing Facilities on Under-Five Mortality}

The housing facilities under this sub-section include water supply, toilets, cooking fuel, and power. The results are summarized and presented in Tables 9-13, with their respective graphical representations (see Figures 6-10).

\section{Impact of Housing Durables on Under-Five Mortality}

The variations of under-five mortality levels with respct to the household durables are examined in Tables 14-16, with their respective graphical representations (see Figures 11-13).

\section{SUMMARY OF THE PROPORTIONALITY OF HOUSING CORRELATES OF UNDER-FIVE MORTALITY}

Among the categorical variables of the housing structures, facilities, and household durables, which manifested highest proportions of the prevalence of proportion of under-five mortality levels, are summarized in the following table (see Table 17).

\section{CONCLUSIONS}

It is believed that this study provides basic inputs for urban planners and policy makers to be engaged in ameliorating the current urban housing conditions, which could contribute to the evaluation of the attainment for the 2015 MDG4 expected target and also for future improvements of urban quality of life.

The remaining task is further undertaken analysis by cross tabulating among the housing characteristics, being controlled for proportion of under-five mortality levels. For example, types of floor cross tabulating by types of wall, controlled for proportion dead, could help focus in upgrading existing housing conditions and also for future urban and housing planning, monitoring, and evaluation programmes.

\section{APPENDIX}

The issues about bivariate frequency distribution of the housing conditions of the urban areas are shown in Tables 18-20. 
Table 5. Impact by Place of Residence

\begin{tabular}{lllll}
\hline Urban area & Ever born & Living & Died (absolute) & Proportion died \\
\hline Capital/Large city & 2,552 & 1,928 & 624 & .2445 \\
Small city & 2,929 & 2,198 & 731 & .2496 \\
Town & 2,468 & 1,836 & 632 & .2561 \\
Total & 7,949 & 5,962 & 1,987 & .2500 \\
\hline
\end{tabular}

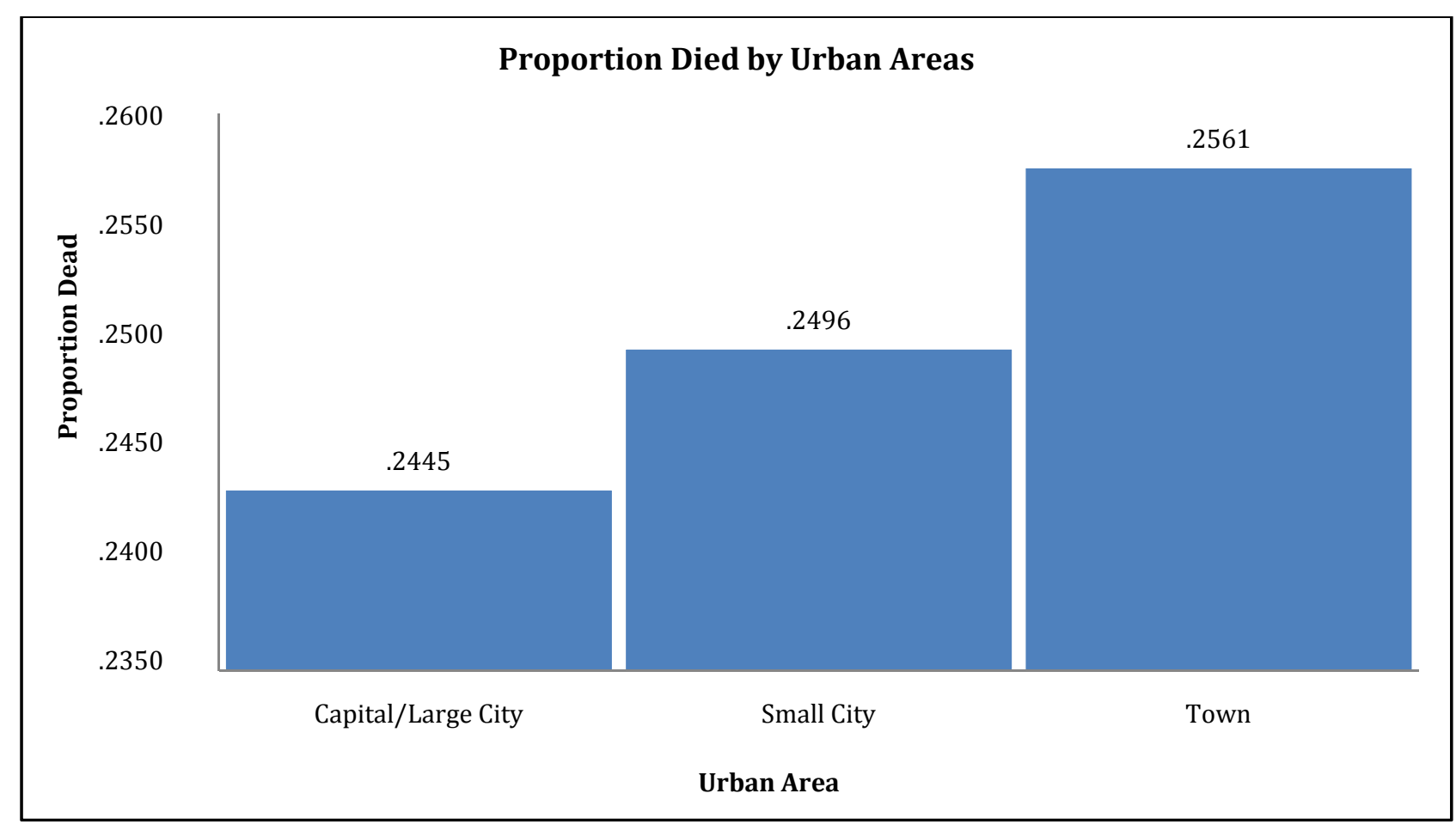

Figure 2. Proprtion Dead by Type of Urban Areas.

Table 6. Construction Material of Floors

\begin{tabular}{lllll}
\hline Types of floor & CEB & Total alive & Deaths (absolute) & Proportion dead \\
\hline Earth/Sand & 1,977 & 1,684 & 293 & .1482 \\
Animal dung & 494 & 409 & 85 & .1721 \\
Wood planks/Reed & 90 & 85 & 7 & .0778 \\
Polished wood & 204 & 193 & 11 & .0539 \\
Vinyl & 1,998 & 1,773 & 225 & .1126 \\
Ceramic tiles & 124 & 118 & 6 & .0484 \\
Cement/Bricks & 1,457 & 1,324 & 133 & .0913 \\
Carpet & 252 & 225 & 27 & .1071 \\
Not usual residents & 158 & 137 & 21 & .1329 \\
Total & 6,754 & 5,948 & 808 & .1196 \\
\hline
\end{tabular}




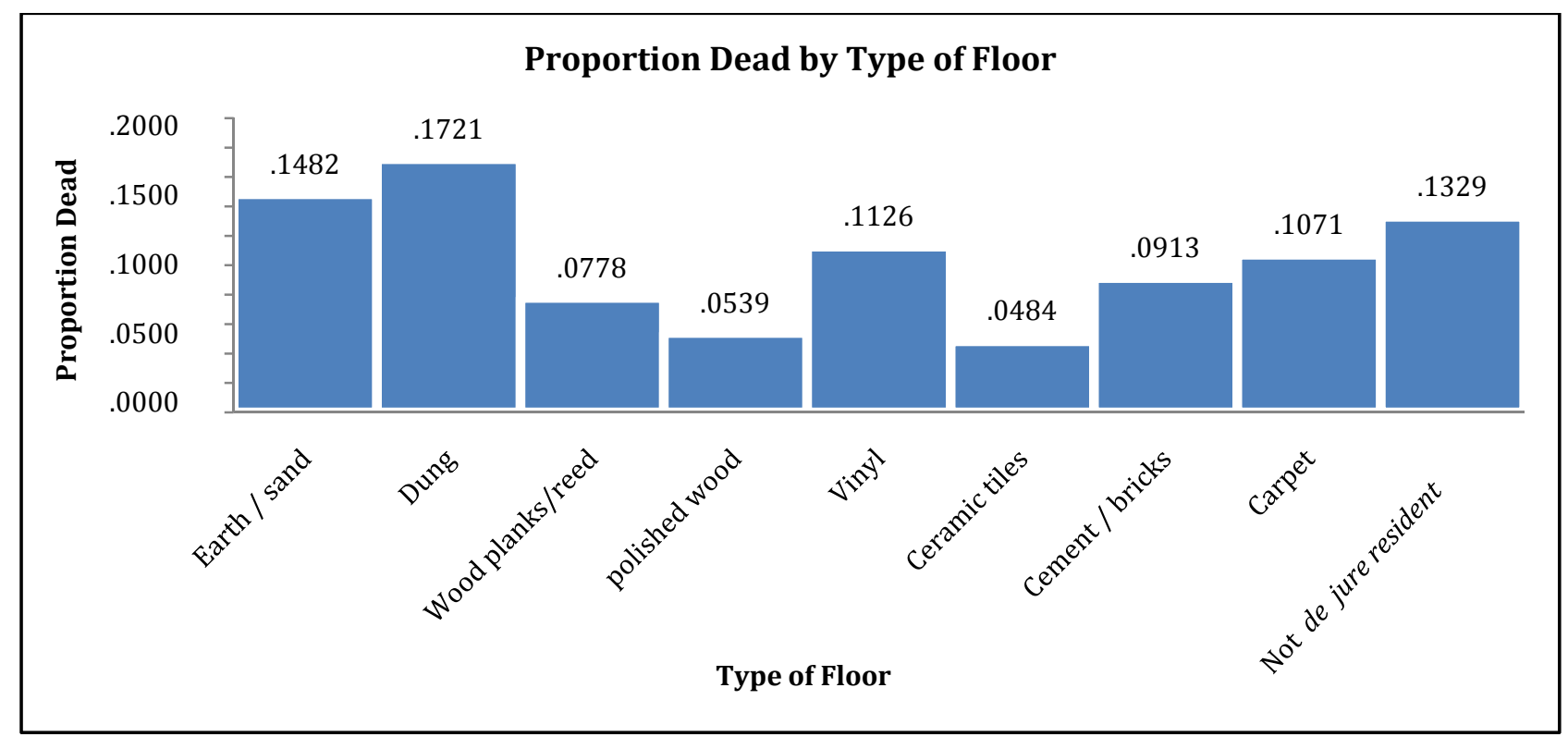

Figure 3. Proportion Dead by Type of Floor.

Table 7. Construction Material of Wall

\begin{tabular}{lllll}
\hline Wall material & CEB & Alive & Dead (absolute) & Proportion dead \\
\hline Unconventional walls & 433 & 293 & 140 & .3233 \\
Bamboo/Wood with mud & 4,404 & 3,853 & 551 & .1251 \\
Stone with mud & 630 & 552 & 78 & .1238 \\
Cement & 177 & 159 & 18 & .1017 \\
Stone with lime/cement & 435 & 395 & 40 & .0920 \\
Cement blocks & 622 & 568 & 54 & .0868 \\
Not de jure resident & 158 & 137 & 21 & .1329 \\
Total & 6,859 & 5,957 & 902 & .1315 \\
\hline
\end{tabular}

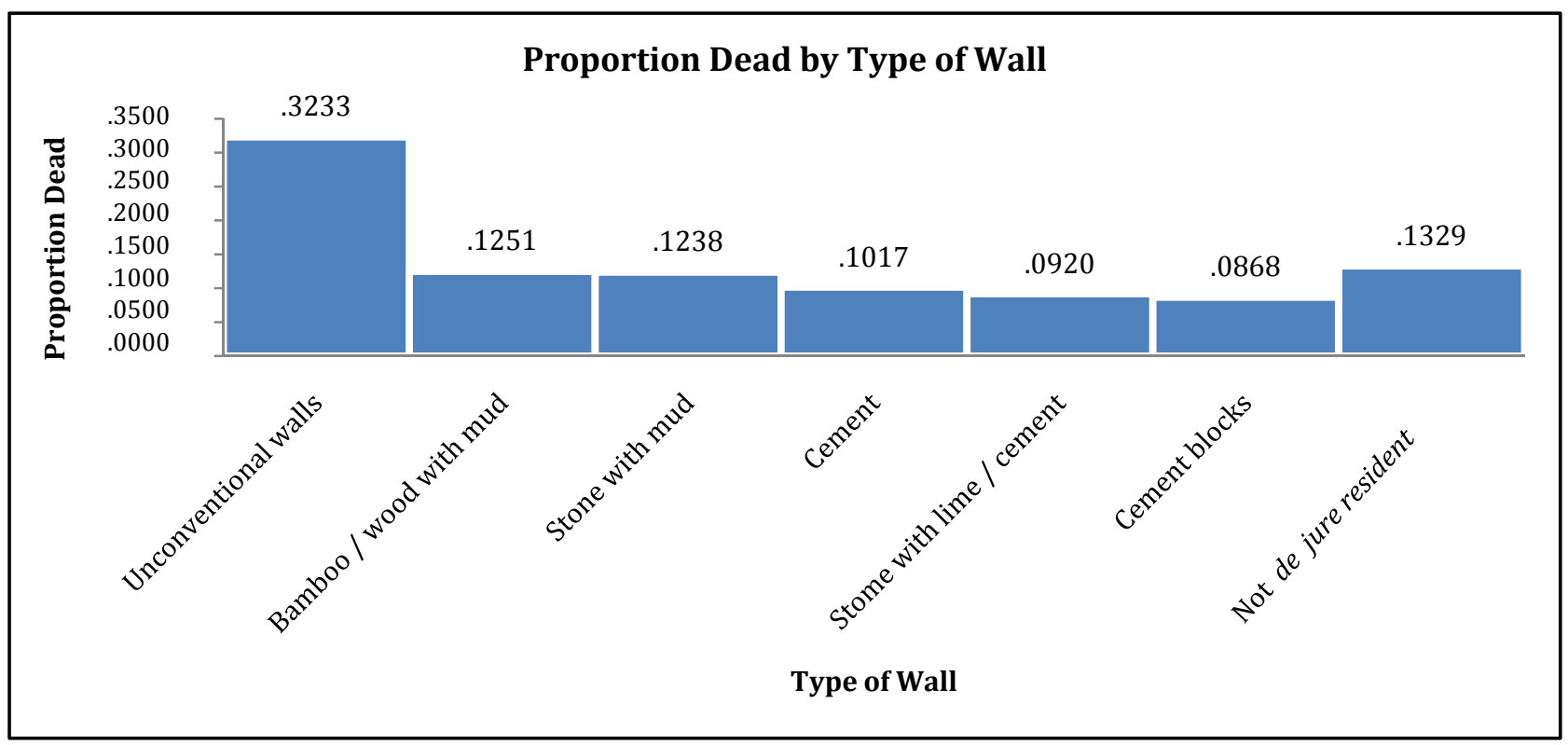

Figure 4. Proportion Dead by Type of Wall. 
Table 8. Construction Material of Roofing

\begin{tabular}{|c|c|c|c|c|}
\hline Roofing material & CEB & Alive & Dead (absolute) & Proportion dead \\
\hline Unconventional roofing & 184 & 149 & 35 & .1902 \\
\hline Thatch/Leaf/Reed & 447 & 337 & 110 & .2461 \\
\hline Wood planks & 79 & 69 & 10 & .1266 \\
\hline Corrugated iron & 5,915 & 5,237 & 678 & .1146 \\
\hline Cement/Concrete & 21 & 21 & 0 & .0000 \\
\hline Not de jure resident & 158 & 137 & 21 & .1329 \\
\hline Total & 6,804 & 5,950 & 854 & .1255 \\
\hline
\end{tabular}

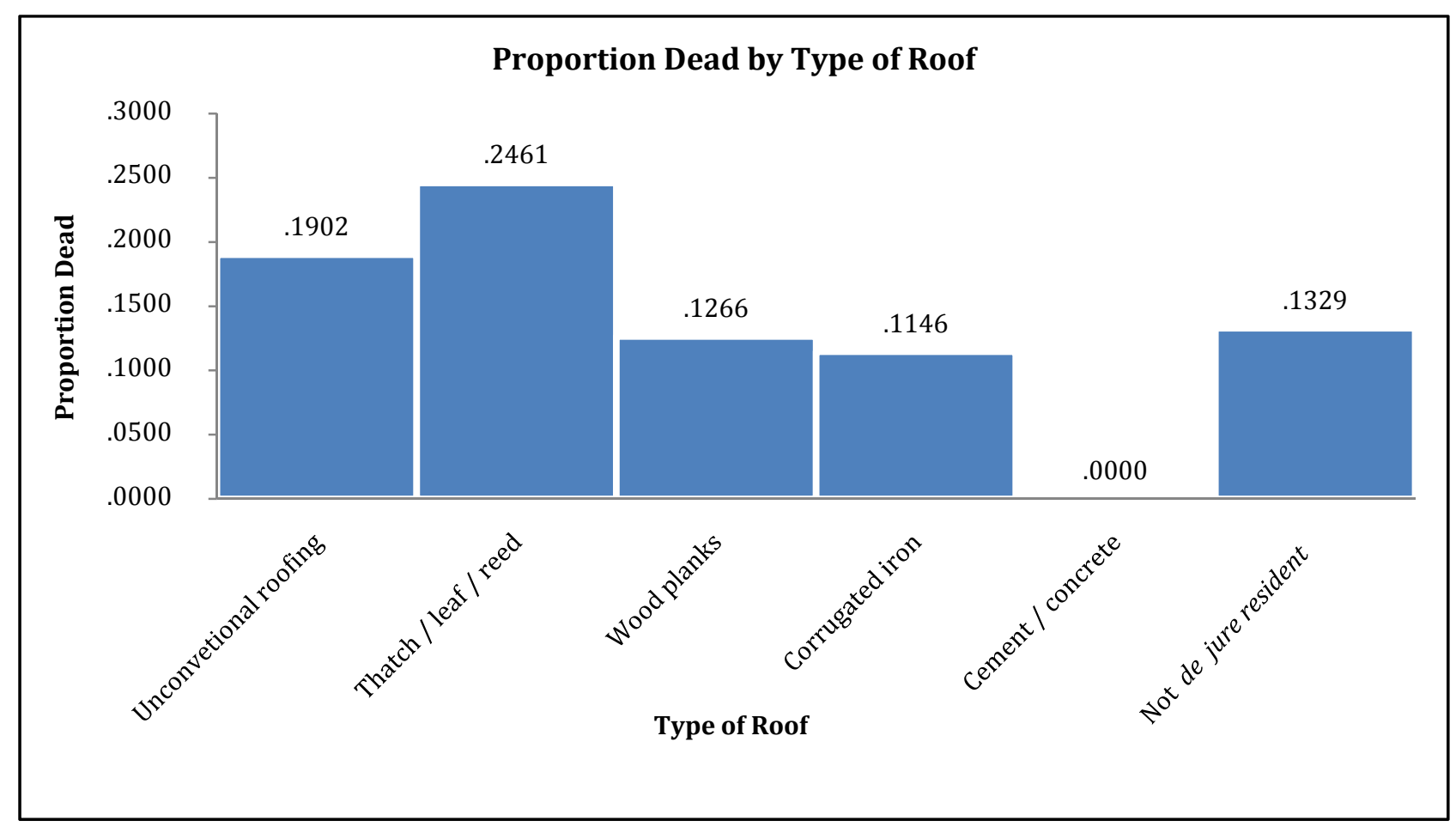

Figure 5. Proportion Dead by Type of Roof.

Table 9. Water Supply

\begin{tabular}{lllll}
\hline Source of drinking water & CEB & Alive & Dead (absolute) & Proportion dead \\
\hline Piped in dwelling & 145 & 130 & 15 & .1034 \\
Piped into compound & 2,712 & 2,485 & 227 & .0837 \\
Piped outside compound & 2,878 & 2,457 & 421 & .1463 \\
Unprotected well/spring & 438 & 372 & 66 & .1507 \\
Protected well/spring & 428 & 369 & 59 & .1379 \\
Not de jure resident & 158 & 137 & 21 & .1329 \\
Total & 6,759 & 5,950 & 809 & .1197 \\
\hline
\end{tabular}




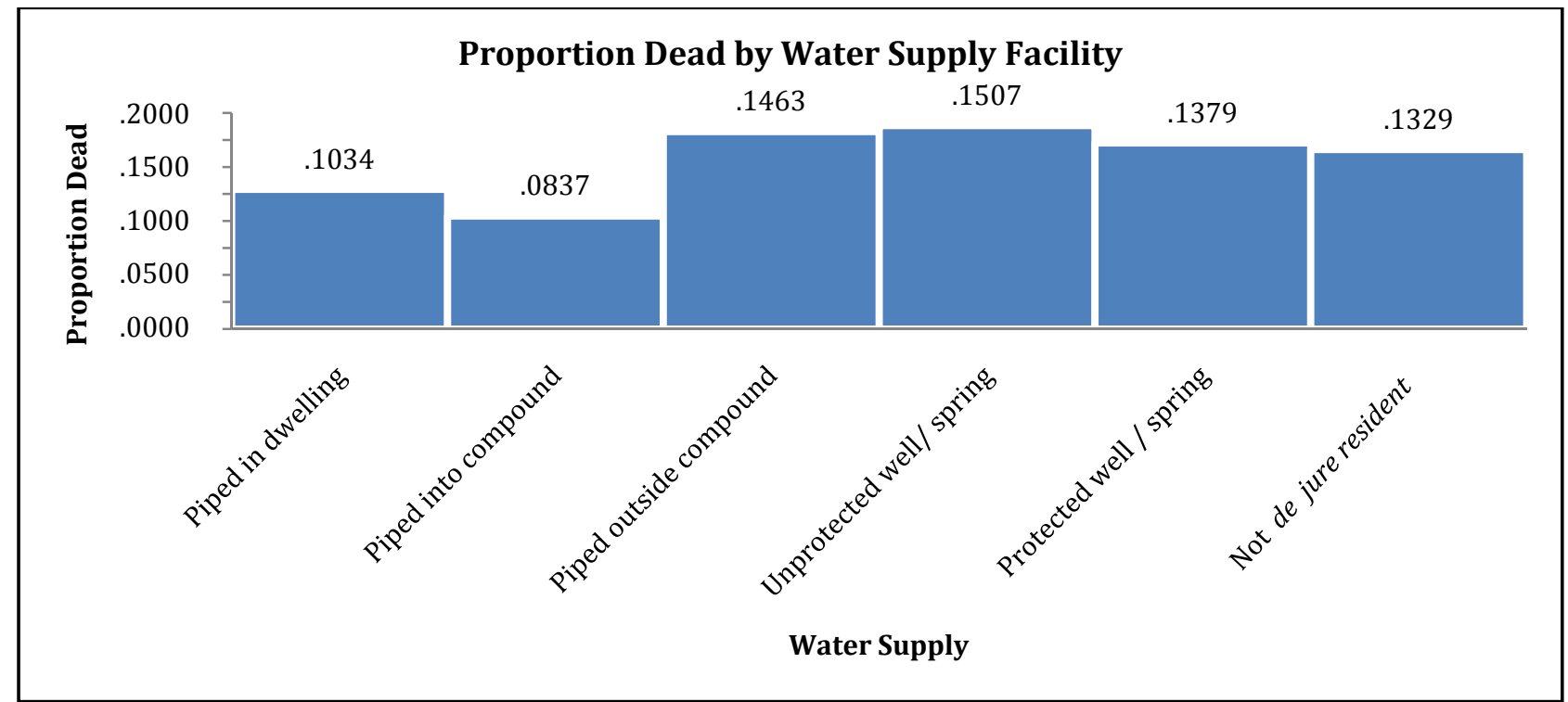

Figure 6. Proprtion Dead by Water Supply Facility.

Table 10. Toilet Facility

\begin{tabular}{lllll}
\hline Type of toilet facility & CEB & Alive & Dead (absolute) & Proportion dead \\
\hline Flush to sewer/septic tank & 166 & 160 & 6 & .0361 \\
Flush to pit latrine & 175 & 157 & 18 & .1029 \\
Ventilated improved pit latrine & 314 & 275 & 39 & .1242 \\
Pit latrine with slab & 2,840 & 2,549 & 291 & .1025 \\
Pit latrine without slab/open pit & 1,971 & 1,719 & 252 & .1279 \\
Composting toilet & 228 & 196 & 32 & .1404 \\
Bucket toilet & 36 & 28 & 8 & .2222 \\
No facility/bush/field & 871 & 729 & 142 & .1630 \\
Not de jure resident & 158 & 137 & 21 & .1329 \\
Total & 6,759 & 5,950 & 809 & .1197 \\
\hline
\end{tabular}

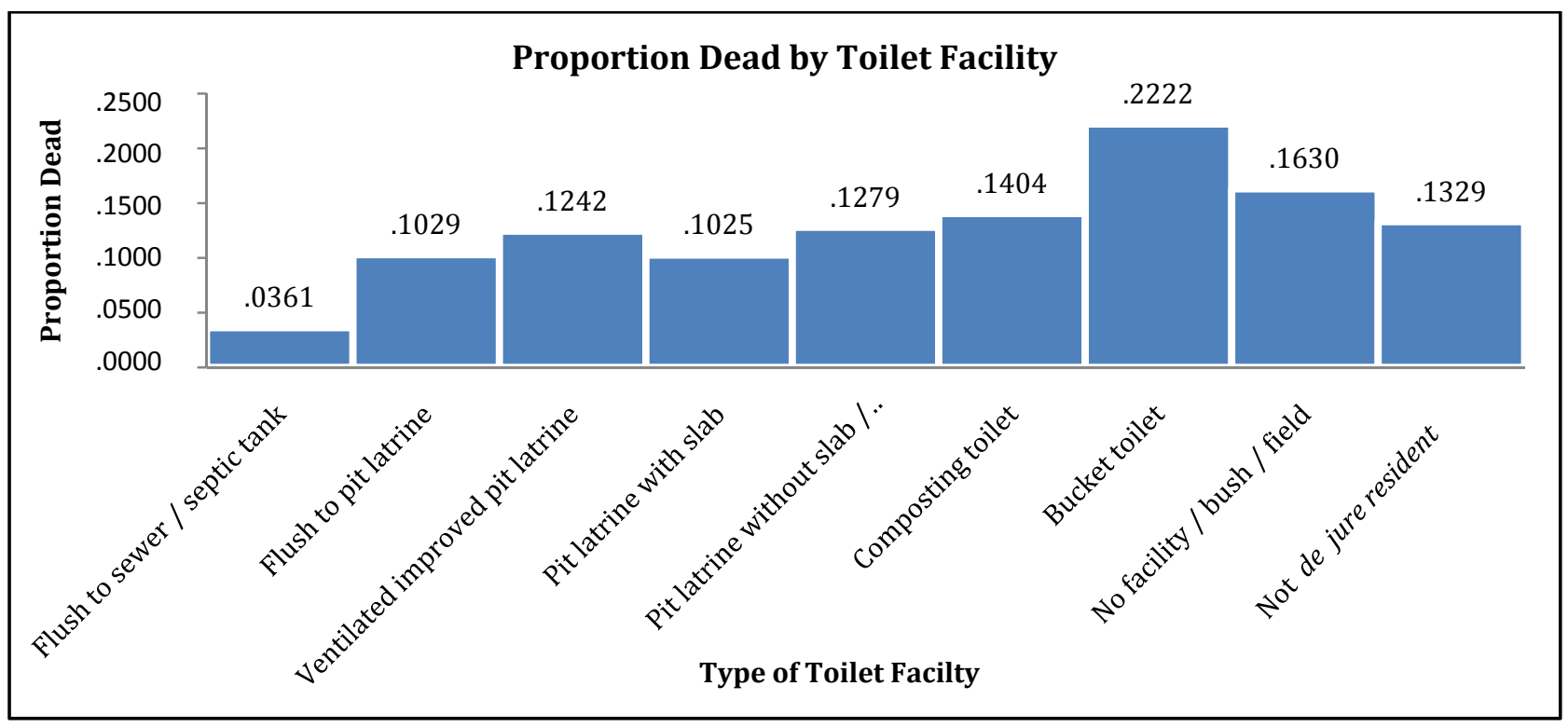

Figure 7. Proprtion Dead by Toilet Facility. 
Table 11. Toilet Sharing Facility

\begin{tabular}{lllll}
\hline Toilet facility shared & CEB & Alive & Dead (absolute) & Proportion dead \\
\hline No & 2,682 & 2,408 & 274 & .1022 \\
Yes & 3,052 & 2,679 & 373 & .1222 \\
Not de jure resident & 158 & 137 & 21 & .1329 \\
Total & 5,892 & 5,224 & 668 & .1134 \\
\hline
\end{tabular}

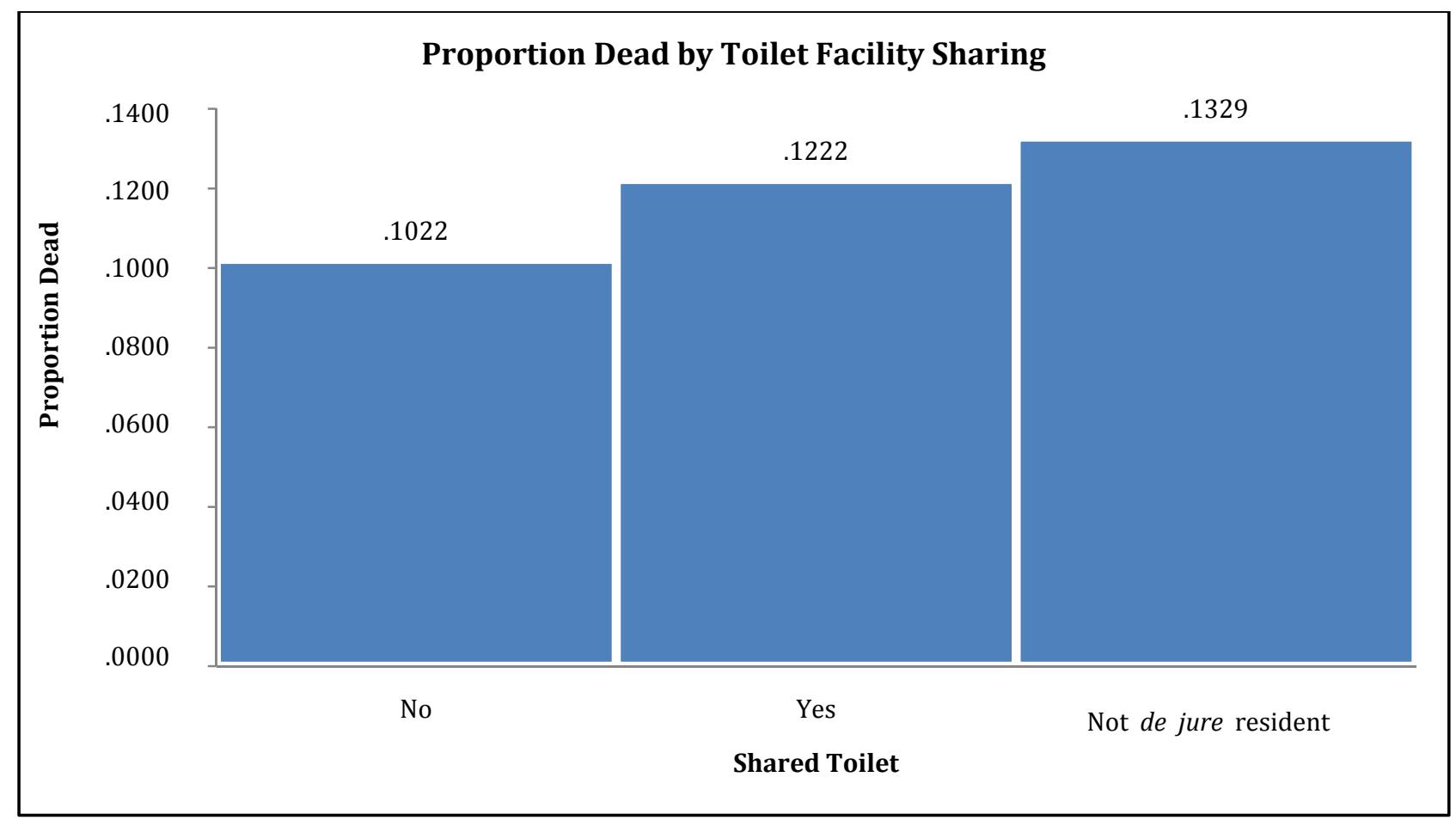

Figure 8. Proportion Dead by Toilet Facility Sharing.

Table 12. Cooking Fuel

\begin{tabular}{lllll}
\hline Type of cooking fuel & CEB & Alive & Dead (absolute) & Proportion dead \\
\hline Electricity & 82 & 77 & 5 & .0610 \\
Natural gas & 84 & 81 & 3 & .0357 \\
Kerosene & 2,083 & 1,891 & 192 & .0922 \\
Charcoal & 1,191 & 1,065 & 126 & .1058 \\
Firewood, straw & 3,102 & $2,, 651$ & 451 & .1454 \\
animal dung & 57 & 47 & 10 & .1754 \\
Not de jure member & 158 & 137 & 21 & .1329 \\
Total & 6,757 & 5,949 & 808 & .1196 \\
\hline
\end{tabular}




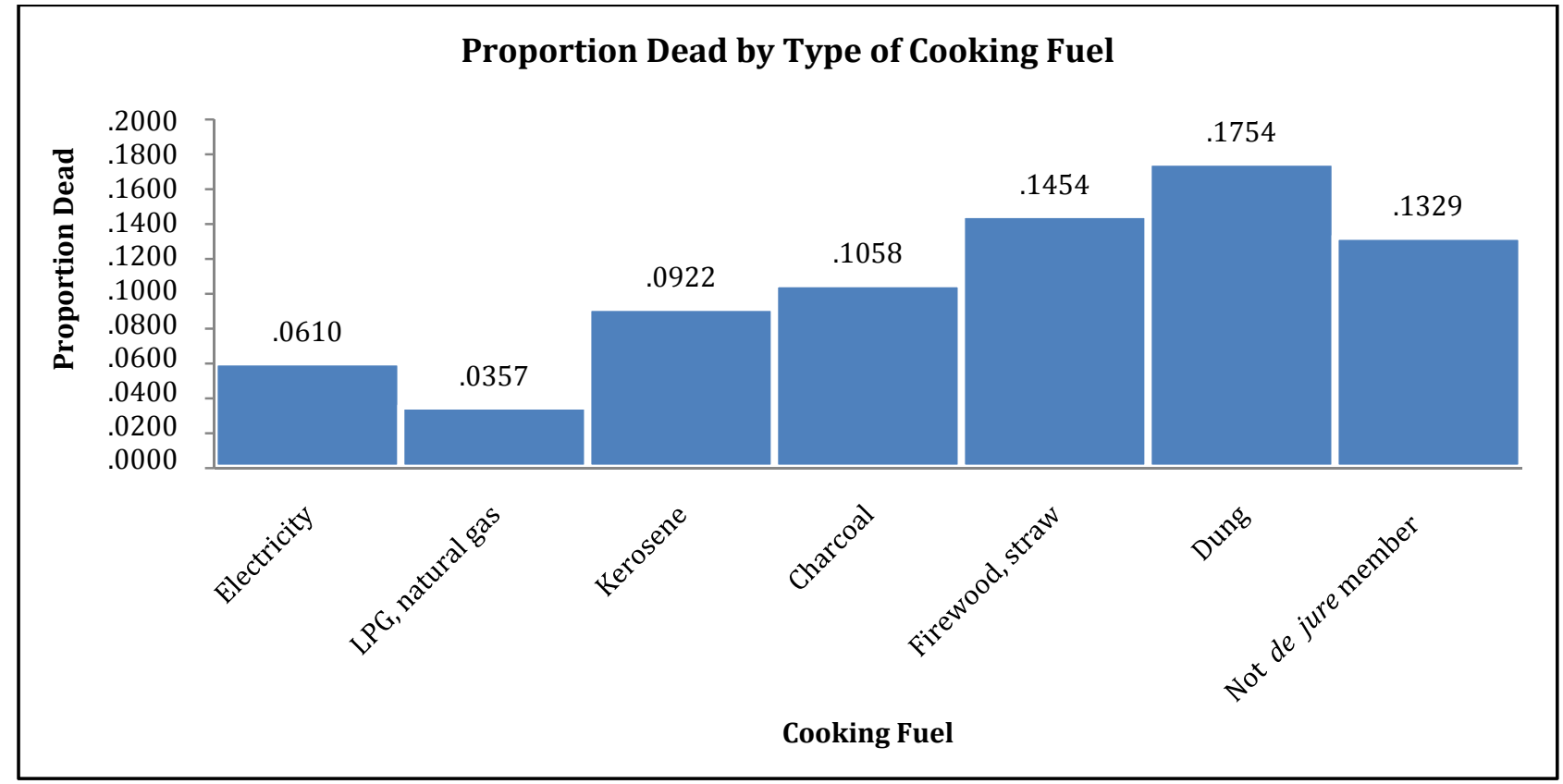

Figure 9. Proportion Dead by Type of Cooking Fuel.

Table 13. Availability of Elecricity and Proprtion Dead

\begin{tabular}{lllll}
\hline Has electricity & CEB & Alive & Dead (absolute) & Proportion dead \\
\hline No & 1,058 & 878 & 180 & .1701 \\
Yes & 5,543 & 4,935 & 608 & .1097 \\
Not de jure resident & 158 & 137 & 21 & .1329 \\
Total & 6,759 & 5,950 & 809 & .1197 \\
\hline
\end{tabular}

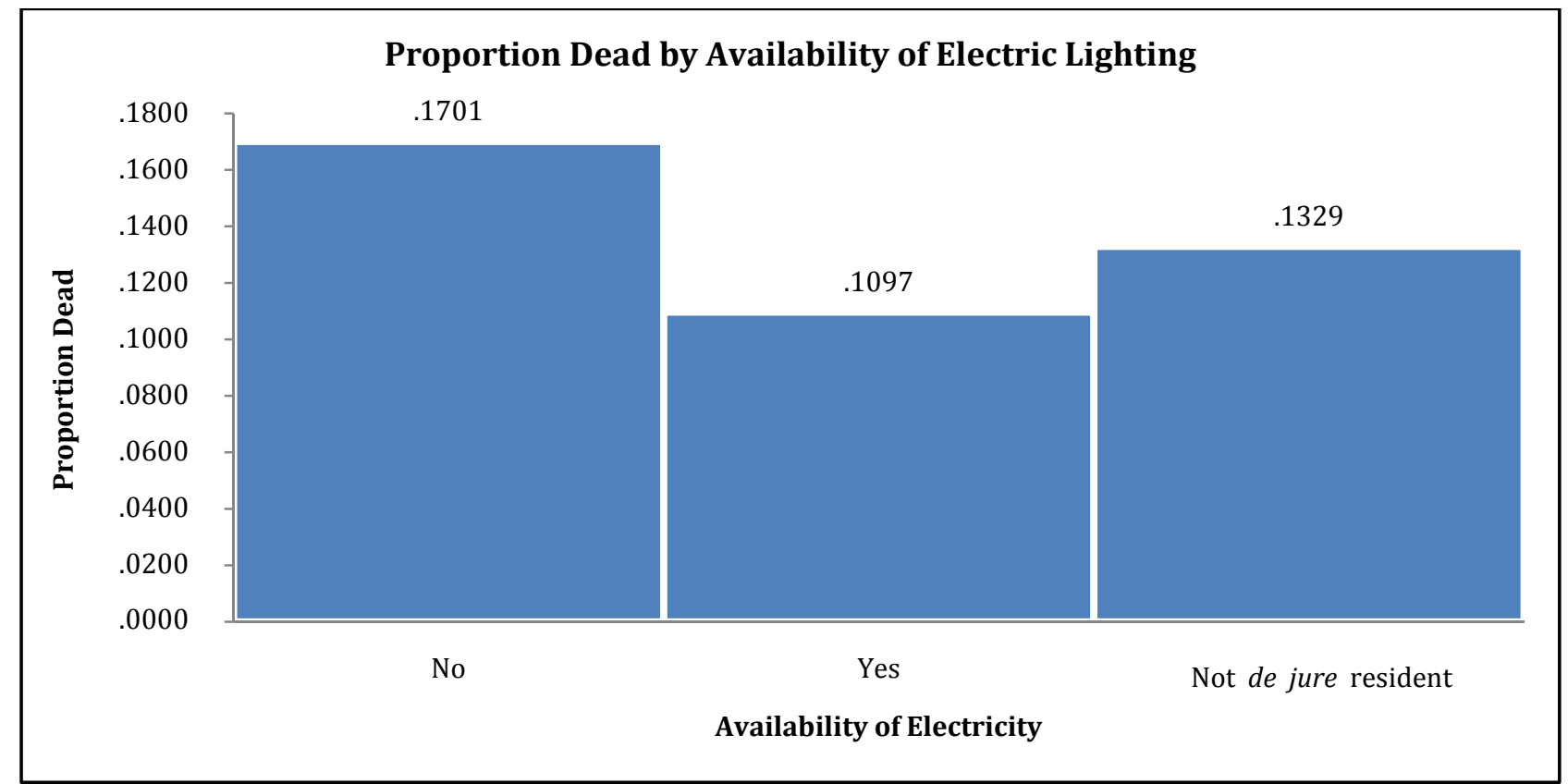

Figure 10. Proportion Dead by Electricity. 
Table 14. Under-Five Mortality Variations With Respect to Radio Availability in a Household

\begin{tabular}{lllll}
\hline Has radio & CEB & Alive & Dead (absolute) & Proportion dead \\
\hline No & 1,382 & 1,144 & 238 & .1722 \\
Yes & 5,219 & 4,669 & 550 & .1054 \\
Not de jure resident & 158 & 137 & 21 & .1329 \\
Total & 6,759 & 5,950 & 809 & .1197 \\
\hline
\end{tabular}

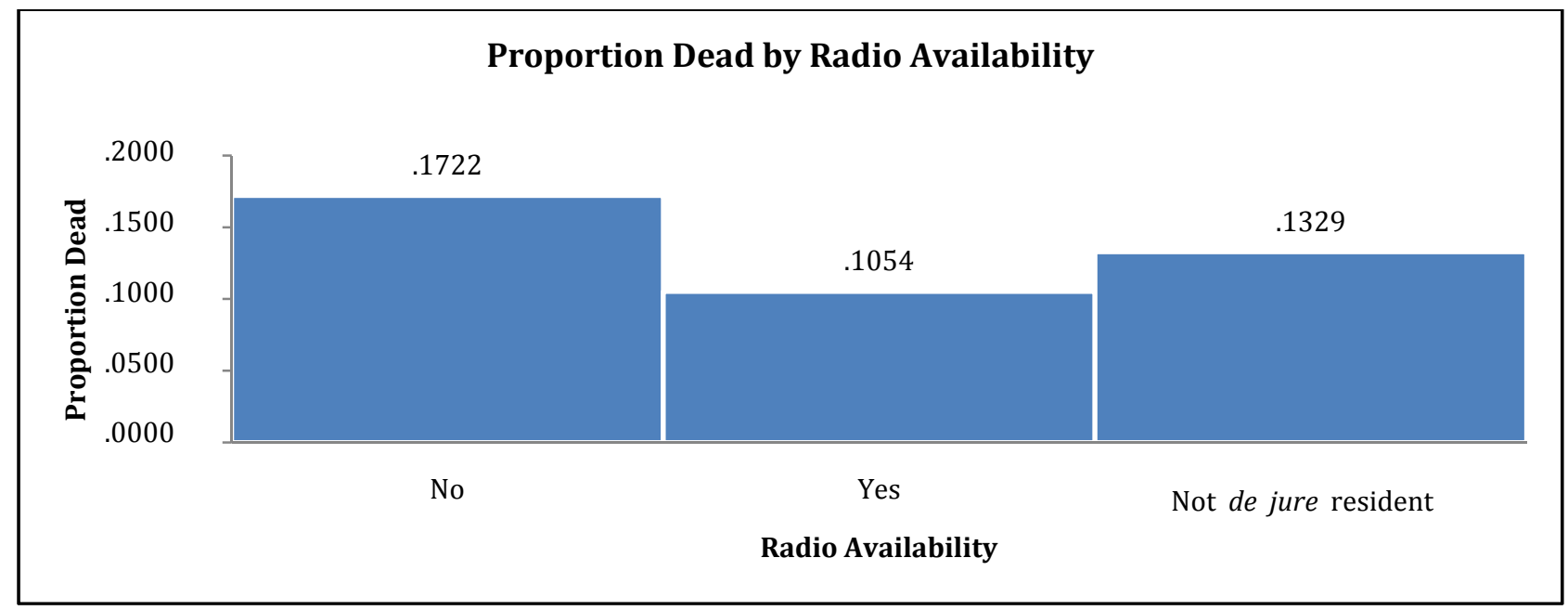

Figure 11. Proportion Dead by Radio Availability.

Table 15. Under-Five Mortality Variations With Respect to Telephone Availability in a Household

\begin{tabular}{lllll}
\hline Has telephone & CEB & Alive & Dead (absolute) & Proportion dead \\
\hline No & 4,321 & 3,708 & 613 & .1419 \\
Yes & 2,274 & 2,100 & 174 & .0765 \\
Not de jure resident & 158 & 137 & 21 & .1329 \\
Total & 6,753 & 5,945 & 808 & .1197 \\
\hline
\end{tabular}

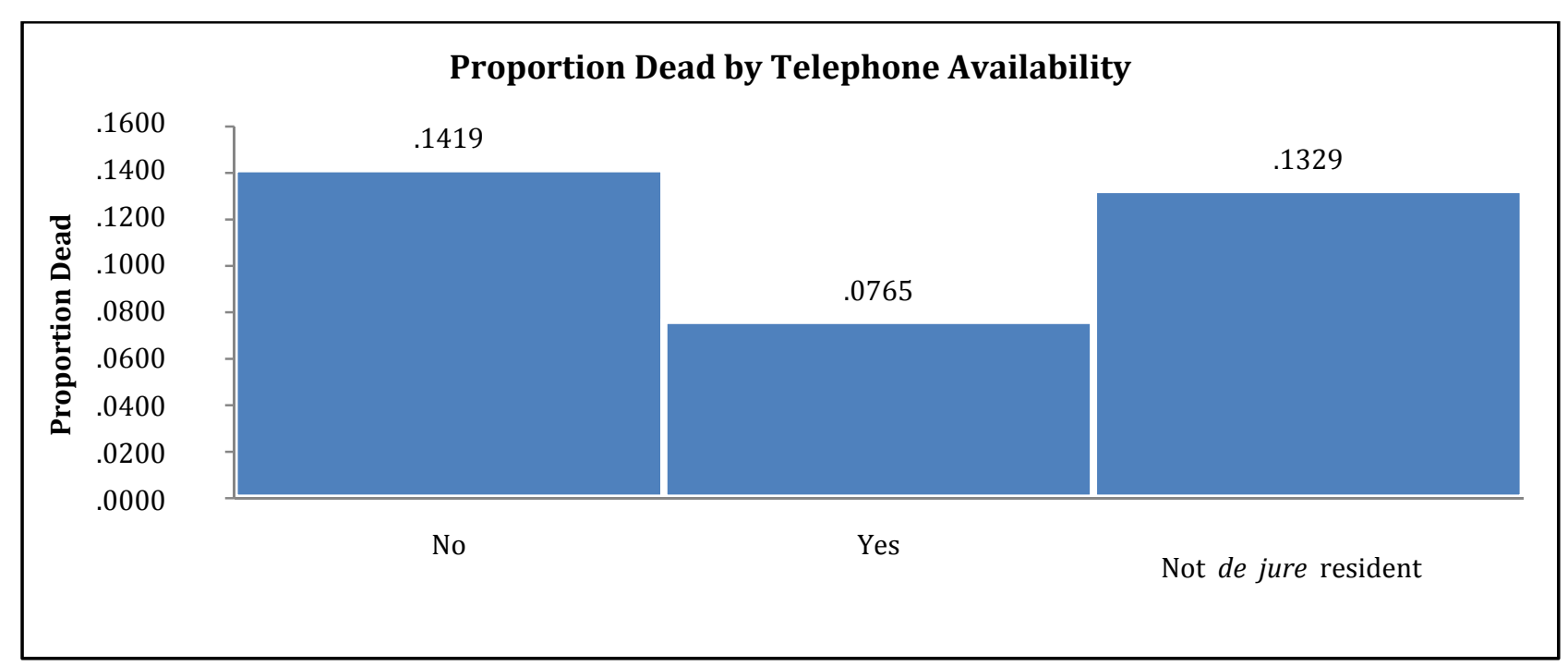

Figure 12. Proprtion Dead by Telephone Availability. 
Table 16. Under-Five Mortality Variations With Respect to TV Availability in a Household

\begin{tabular}{lllll}
\hline Has TV & CEB & Alive & Dead (absolute) & Proportion dead \\
\hline No & 3,697 & 3,143 & 554 & .1499 \\
Yes & 2,904 & 2,670 & 234 & .0806 \\
Not de jure resident & 158 & 137 & 21 & .1329 \\
Total & 6,759 & 5,950 & 809 & .1197 \\
\hline
\end{tabular}

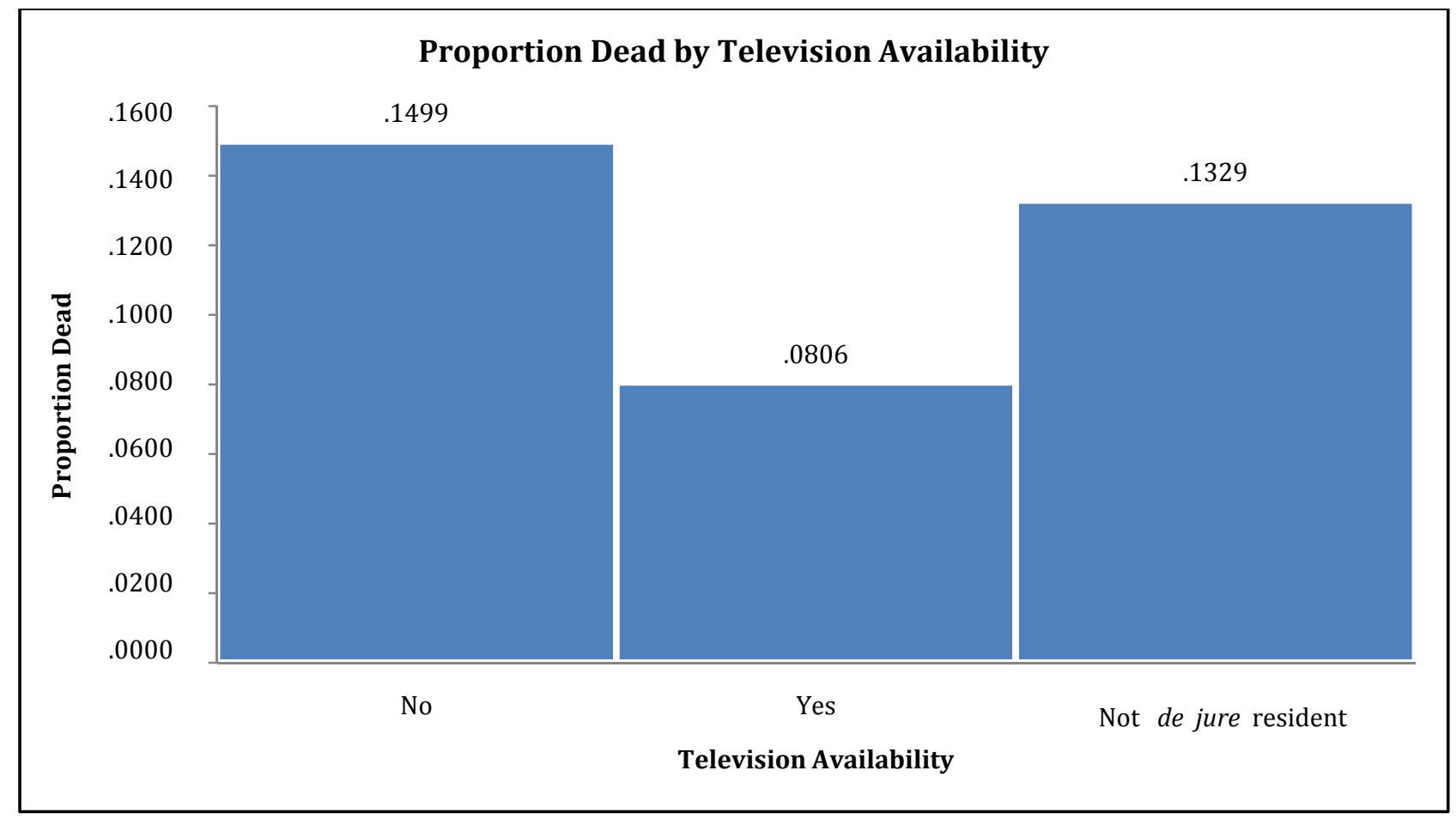

Figure 13. Proprtion Dead by Television Availability.

Table 17. Summary Results of the Study

\begin{tabular}{|l|l|}
\hline Housing characteristics & Highest proportion dead \\
\hline 1. Housing structure & \\
\hline Floor: animal dung & 1721 \\
\hline Wall: unconventional material & .3233 \\
\hline Roofing: thatched leave/reed & .2461 \\
\hline 2. Housing facilities & \\
\hline Water: unprotected well/spring & 1507 \\
\hline Toilet: shared pit latrine, use of bucket/bush & .2222 \\
\hline Lightning: no electric power & 1701 \\
\hline Cooking: kerosene, fire wood/straw, charcoal & 1754 \\
\hline 3. Household durables & \\
\hline No household radio & .1722 \\
\hline No household telephone & 1419 \\
\hline No household TV & 1499 \\
\hline
\end{tabular}


Table 18. Bivariate Frequency Distribution of Housing Structure by Urban Classifications

\begin{tabular}{|c|c|c|c|c|c|}
\hline \multirow{2}{*}{\multicolumn{2}{|c|}{ Housing structure }} & \multicolumn{4}{|c|}{ Classification of urban areas } \\
\hline & & \multirow{2}{*}{\begin{tabular}{|l} 
Capital, large city \\
22.8
\end{tabular}} & \multirow{2}{*}{$\begin{array}{l}\text { Medium city } \\
46.2\end{array}$} & \multirow{2}{*}{$\begin{array}{l}\text { Small town } \\
15.6\end{array}$} & \multirow{2}{*}{\begin{tabular}{|l|}
$\begin{array}{l}\text { Column total } \\
(\%)\end{array}$ \\
30.2 \\
\end{tabular}} \\
\hline \multirow{5}{*}{ Types of wall } & Modern & & & & \\
\hline & Bamboo/Wood/Mud & 69.8 & 45.3 & 74.6 & 61.5 \\
\hline & Others & 7.4 & 8.5 & 9.8 & 8.3 \\
\hline & Total & $100.0(1,812)$ & $100.0(1,663)$ & $100.0(948)$ & 4,423 \\
\hline & Row total $(\%)$ & 41.0 & 37.6 & 21.4 & 100.0 \\
\hline \multirow{5}{*}{ Types of floor } & Vinyl/Cement bricks & 67.9 & 66.2 & 26.3 & 58.4 \\
\hline & Carpet/Earth/Dung & 27.3 & 30.3 & 71.0 & 37.7 \\
\hline & Others & 4.8 & 3.5 & 2.7 & 3.9 \\
\hline & Total & $100.0(1,812)$ & $100.0(1,663)$ & $100.0(948)$ & 4,423 \\
\hline & Row total (\%) & 41.0 & 37.6 & 21.4 & 100.0 \\
\hline \multirow{5}{*}{ Types of roof } & Corrugated iron sheets & 94.3 & 92.5 & 75.7 & 88.8 \\
\hline & Thatch/Leaf/Reed & 0.4 & 2.5 & 15.9 & 5.1 \\
\hline & Others & 5.3 & 4.9 & 8.4 & 6.1 \\
\hline & Total & $100.0(1,812)$ & $100.0(1,660)$ & $100.0(948)$ & 4,420 \\
\hline & Row total (\%) & 41.0 & 37.6 & 21.4 & 100.0 \\
\hline
\end{tabular}

Table 19. Summary of Frequency Distribution of Housing Facilities

\begin{tabular}{|c|c|c|c|c|c|}
\hline \multirow{2}{*}{\multicolumn{2}{|c|}{ Housing facilities }} & \multicolumn{4}{|c|}{ Classification of urban areas } \\
\hline & & \multirow{2}{*}{\begin{tabular}{|l} 
Capital, large city \\
71.0
\end{tabular}} & \multirow{2}{*}{\begin{tabular}{|l} 
Medium city \\
49.0
\end{tabular}} & \multirow{2}{*}{$\begin{array}{l}\text { Small town } \\
25.3\end{array}$} & \multirow{2}{*}{\begin{tabular}{|l} 
Column total (\%) \\
51.1 \\
\end{tabular}} \\
\hline \multirow{5}{*}{$\begin{array}{l}\text { Types of } \\
\text { water } \\
\text { supply }\end{array}$} & Pipe in dwelling/compound & & & & \\
\hline & Pipe outside compound & 24.0 & 43.6 & 42.8 & 36.9 \\
\hline & Unprotected well/spring & 5.0 & 7.4 & 31.9 & 2.0 \\
\hline & Total & $100.0(1,812)$ & $100.0(1,663)$ & $100.0(948)$ & 4,423 \\
\hline & Row total (\%) & 41.0 & 37.6 & 21.4 & 100.0 \\
\hline \multirow{5}{*}{$\begin{array}{l}\text { Type of } \\
\text { toilet facility }\end{array}$} & Pit latrine with open pit & 69.3 & 75.0 & 69.3 & 71.5 \\
\hline & Flush to sewer/septic tank & 19.7 & 8.5 & 6.5 & 12.8 \\
\hline & Others (bucket, bush, etc.) & 11.0 & 3.5 & 24.2 & 15.7 \\
\hline & Total & $100.0(1,812)$ & $100.0(1,663)$ & $100.0(948)$ & 4,423 \\
\hline & Row total (\%) & 41.0 & 37.6 & 21.4 & 100.0 \\
\hline \multirow{5}{*}{$\begin{array}{l}\text { Toilet } \\
\text { facilities } \\
\text { shared }\end{array}$} & No & 34.1 & 42.9 & 53.3 & 43.0 \\
\hline & Yes & 60.7 & 53.3 & 43.5 & 57.5 \\
\hline & Not de jure & 5.1 & 3.8 & 3.2 & 4.5 \\
\hline & Total & $100.0(1,755)$ & $100.0(1,531)$ & $100.0(758)$ & $100.0(4,044)$ \\
\hline & Row total (\%) & 43.4 & 37.9 & 18.7 & 100.0 \\
\hline
\end{tabular}


Table 19 continued

\begin{tabular}{|c|c|c|c|c|c|}
\hline \multirow{2}{*}{\multicolumn{2}{|c|}{ Housing facilities }} & \multicolumn{4}{|c|}{ Classification of urban areas } \\
\hline & & \multirow{2}{*}{\begin{tabular}{|l} 
Capital, large city \\
69.0
\end{tabular}} & \multirow{2}{*}{\begin{tabular}{|l} 
Medium city \\
29.9
\end{tabular}} & \multirow{2}{*}{$\begin{array}{l}\text { Small town } \\
4.2\end{array}$} & \multirow{2}{*}{\begin{tabular}{|l} 
Column total (\%) \\
40.5 \\
\end{tabular}} \\
\hline \multirow{5}{*}{ Cooking fuel } & Kerosene & & & & \\
\hline & Firewood/Straw/Charcoal & 21.2 & 60.7 & 92.1 & 51.3 \\
\hline & Electricity, natural gas, etc. & 9.8 & 9.4 & 3.7 & 8.2 \\
\hline & Total & $100.0(1,812)$ & $100.0(1,663)$ & $100.0(944)$ & 4,419 \\
\hline & Row total (\%) & 41.0 & 37.6 & 21.4 & 100.0 \\
\hline \multirow{5}{*}{$\begin{array}{l}\text { Has } \\
\text { electricity }\end{array}$} & No & 2.6 & 1.9 & 31.8 & 8.7 \\
\hline & Yes & 92.4 & 94.6 & 65.7 & 87.2 \\
\hline & Other & 5.0 & 3.5 & 2.5 & 4.1 \\
\hline & Total & $100.0(1,812)$ & $100.0(1,663)$ & $100.0(948)$ & $100.0(4,423)$ \\
\hline & Row total (\%) & 41.0 & 37.6 & 21.4 & 100.0 \\
\hline
\end{tabular}

Table 20. Availability of Households Durables

\begin{tabular}{|c|c|c|c|c|c|}
\hline \multirow{2}{*}{\multicolumn{2}{|c|}{ Household durables }} & \multicolumn{4}{|c|}{ Classification of urban areas } \\
\hline & & \multirow{2}{*}{\begin{tabular}{|l} 
Capital, large city \\
6.5
\end{tabular}} & \multirow{2}{*}{$\begin{array}{l}\text { Medium city } \\
12.1\end{array}$} & \multirow{2}{*}{\begin{tabular}{|l} 
Small town \\
29.7
\end{tabular}} & \multirow{2}{*}{\begin{tabular}{|l} 
Column total $(\%)$ \\
13.6
\end{tabular}} \\
\hline \multirow{5}{*}{ Has radio } & No & & & & \\
\hline & Yes & 88.5 & 84.4 & 67.7 & 82.5 \\
\hline & Not de jure & 5.0 & 3.5 & 2.5 & 3.9 \\
\hline & Total & $100.0(1,812)$ & $100.0(1,663)$ & $100.0(948)$ & 4,423 \\
\hline & Row total (\%) & 41.0 & 37.6 & 21.4 & 100.0 \\
\hline \multirow{5}{*}{ Has television } & No & 28.0 & 43.3 & 80.2 & 44.9 \\
\hline & Yes & 67.0 & 53.2 & 17.3 & 51.2 \\
\hline & Not de jure & 5.0 & 3.5 & 2.5 & 3.9 \\
\hline & Total & $100.0(1,812)$ & $100.0(1,663)$ & $100.0(948)$ & 4,423 \\
\hline & Row total (\%) & 41.0 & 37.6 & 21.4 & 100.0 \\
\hline \multirow{5}{*}{ Has telephone } & No & 38.1 & 58.9 & 83.0 & 55.5 \\
\hline & Yes & 57.0 & 37.7 & 14.5 & 40.6 \\
\hline & Not de jure & 5.0 & 3.5 & 2.5 & 3.9 \\
\hline & Total & $100.0(1,812)$ & $100.0(1,660)$ & $100.0(948)$ & 4,420 \\
\hline & Row total (\%) & 41.0 & 37.6 & 21.4 & 100.0 \\
\hline
\end{tabular}

\section{Note}

1. Neonatal (NN) Mortality: It is the probability of dying within the first month of live birth; Post-neonatal (PNN) Mortality: It is the probability of dying which consists those passing away after completing the first month of live birth, but before celebrating the first year of live birth; Infant Mortality (IMR-1q0): Infant Mortality $=\mathrm{NN}+\mathrm{PNN}$ : probability of dying before celebrating the first year of live birth; Child Mortality (4q1): probability of dying between the first and the fifth birth year; Under-Five Mortality (5q0): probability of dying between live birth and before celebrating their fifth birth day.

\section{References}

Black, R. E., C. G. Victora, S. P. Walker, Z. A. Bhutta, P. 
Christian, M. de Onis, ... Maternal and Child Nutrition Study Group. 2013. "Maternal and Child Undernutrition and Overweight in Low-Income in Middle-Income Countries.” Lancet 382(9890):396.

CSA (Central Statistical Agency). 2007. 2007 National Population and Housing Census of Ethiopia.

Dherani M. 2008. “Indoor Pollution From Unprocessed Solid Fuel Use and Pneumonia Risk in Children Aged Five Years: A Systematic Review and Meta-analysis.” Bulletin of the WHO 86:390-398.

Hamdan, G. 1964. "Capitals of the New Africa." Economic Geography 40(3):239-253.

Kumar, P. P. and G. File. 2010. "Infant and Child Mortality in Ethiopia: A Statistical Analysis Approach.” Ethiopian Journal of Education and Science 5(2):51-57.

MUDH (Ministry of Urban Development and Housing). 1980. Data on Housing Survey Conditions. MUDH, Addis Abeba.

Nag, M. 1988. “A Framework for the Study of Proximate Determinants of Infant Mortality in Less Developed Countries." Pp. 363-373 in Infant Mortality in India: Differentials and Determinants, edited by A. K. Jain and P. Visaria. New Delhi, Newbury Park, London: Sage Publications.

Obcraft, J. N. and J. W. McDonald. 2010. "Demographic Determinants of Infant and Early Child Mortality: A Comparative Analysis of Population Studies.” A Journal of Demography 39(3):363-385.

Ram, U. 2012. Neonatal and Under-Five Mortality in 597 Indian Districts: Estimates From National Demographic and Mortality Surveys.

Smith, K. R., J. P. McCracken, M. W. Weber, A. Hubbard, A. Jenny, L. M. Thompson, ... N. Bruce. 2011. "Effect of Reduction in Household Air Pollution on Childhood Pneumonia in Guatemala: A Randomized Controlled Trial.”
Lancet 378(9804):1717-1726.

Sokoma, O. 1985. Urban Primacy in Developing Countries: The Case of Mali. Retrieved (http://www.pubmed.gov).

The Guardian. 1990. Infant and Child Mortality, Global MDG, UN/UNICEF 2013 Reports.

UN Children's Fund/WHO. 2004. Low Birth Weight: Country, Regional and Global Estimates. New York: UNICEF.

UN Inter-agency Group for Child Mortality Estimation. 2012. Levels \& Trends in Child Mortality. UNICEF.

UN/UNICEF (United Nations International Children's Emergency Fund). 2012. Child Mortality Estimation: Levels \& Trends in Child Mortality. New York: UN Children's Fund, World Population Prospects.

UNECA (United Nations Economic Commission for Africa). 1995. Population and Sustainable Development With Reference to Linkages Among Environment, Urbanization, and Migration in ECA Member States. Addis Abeba, Ethiopia.

UNICEF (United Nations International Children's Emergency Fund). 2012. Infant and Child Mortality. Global MDG, UN/UNICEF, 2013 Reports.

WHO (World Health Organization)/World Bank. 2004. Levels and Trends of Child Malnutrition. New York: UNICEF.

\section{Bio}

Hadgu Bariagaber, Ph.D., associate professor, Department of Population Studies, University of Botswana; research fields: interrelationship between population variables and development planning, monitoring and evaluation, the multidimentionality of poverty, the demographic dividends of high/low population growth of developing and developed societies, urbanization and migration at country continental and global levels and implications on development. 